\title{
Study of Water Droplets Behavior on Electrical Machine Insulation under the Influence of Uniform Electric Fields: the Influence of Some Parameters on Mica Sheets
}

\author{
S. Maslougkas \\ Democritus University of Thrace, Department of \\ Electrical and Computer Engineering, Power Systems \\ Laboratory, 67100 Xanthi, Greece \\ sotimas1@ee.duth.gr
}

\begin{abstract}
Mica sheets are a vital component of electrical machine insulation. Although great attention has been paid to partial discharges and their deteriorating effect on such insulation, relatively little attention has been given to surface discharges. This paper investigates the effect of water droplets, their volume, their conductivity, their positioning as well as their number on the flashover voltage of mica sheets. It is indicated that all the above mentioned parameters influence the flashover voltage.
\end{abstract}

Keywords-insulation; machine; field; electric; mica;discharge; water; droplet; flashover

\section{INTRODUCTION}

Electric machines are a crucial part of an electric power system and their reliability highly depends on the durability of the insulation. The maximum operating temperature of an electric machine is about $200^{\circ} \mathrm{C}$. An electrical machine is subjected also to mechanical vibrations. The presence of humidity and chemicals can also corrode the insulation of an electrical machine. One can easily conclude that the role of the electric machine insulation is not only to keep the live parts separated from the grounded ones but also to endure the mechanical, thermal and chemical stresses. In other words, such insulation may suffer from multiple stresses, which far too often apply at the same time. The result of these stresses is the creation of voids that lead to the increase of partial discharges [1-4]. The combination of mica and epoxy resin constitutes the basic insulation component of an electric machine due to its ability to withstand the harsh conditions of the operating environment. In this study, a series of experiments was conducted with mica sheets, which are the hardest part of electrical machine insulation. The behavior of water droplets on mica sheets under the influence of uniform electric fields was studied. The experimental parameters studied were the water conductivity, the number, the position and the volume of the droplets and the surface roughness of the mica sheets [5].

\author{
M. G. Danikas \\ Democritus University of Thrace, Department of \\ Electrical and Computer Engineering, Power Systems \\ Laboratory, 67100 Xanthi, Greece \\ mdanikas@ee.duth.gr
}

\section{EXPERIMENTAL SETUP}

\section{A. High voltage supply}

The voltage source (power grid) is connected to the insulation transformer. Next, the variable autotransformer decreases the voltage between $0-140 \mathrm{~V}$ and supplies the low voltage winding of the $100 \mathrm{~V} / 20 \mathrm{kV}$ step up transformer. The step up transformer is a dry type transformer insulated by epoxy resin. The maximum voltage can be reached is $24 \mathrm{kV}$ (1.2 times the nominal output voltage). On the low voltage side of the step up transformer there's a digital voltmeter. A circuit breaker interrupts the circuit before the insulation transformer (Figure 1).

\section{B. Electrodes}

The electrodes are made of brass and their shape is that of a half cylinder with rounded edges. During their construction, attention was given on the surface smoothness because a smooth surface creates a uniform electric field (Figure 2).

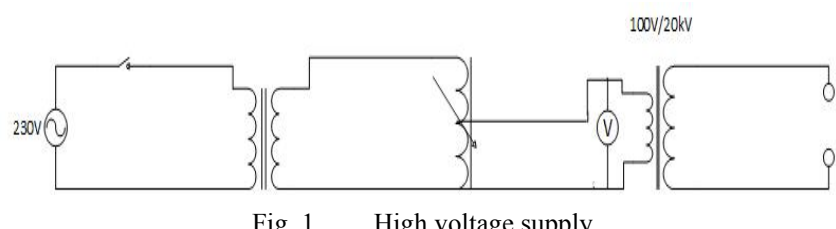

Fig. 1. High voltage supply.

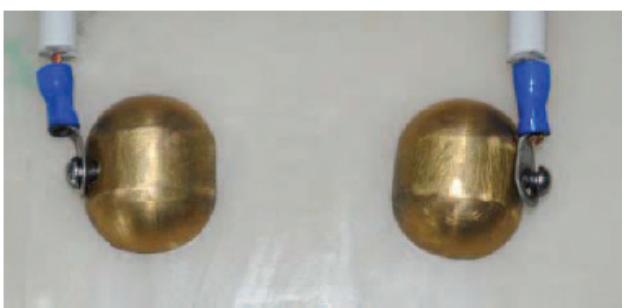

Fig. 2. The electrodes of the experimental setup. Their distance is $2.5 \mathrm{~cm}$. 


\section{Water samples}

The values of electric conductivity of the water samples used were $1,4 \mu \mathrm{S} / \mathrm{cm}, 100 \mu \mathrm{S} / \mathrm{cm}, 200 \mu \mathrm{S} / \mathrm{cm}, 500 \mu \mathrm{S} / \mathrm{cm}, 1000$ $\mu \mathrm{S} / \mathrm{cm}, 2000 \mu \mathrm{S} / \mathrm{cm}, 5000 \mu \mathrm{S} / \mathrm{cm}$ and $10000 \mu \mathrm{S} / \mathrm{cm}$. Distilled water conductivity is approximately $1,4 \mu \mathrm{S} / \mathrm{cm}$ at $25^{\circ} \mathrm{C}$ and it is increased when $\mathrm{NaCl}$ is added. $\mathrm{By}$ adding $\mathrm{NaCl}$ and counting the conductivity (using a digital conductivity meter) the above mentioned values were obtained.

\section{Surface roughness}

The surface roughness is calculated by the vertical divergence of the real surface from the ideal one. If the vertical distances are high, the surface is rough. Using Pertometer M4P, the roughness of the mica paper samples was specified (Figure 3 ). The needle of the device moves on a line segment on the sample surface while the surface abnormalities move the needle vertically. A sensor converts the needle movement to an electric signal which is processed by the microprocessor. After completing the calculations the device prints the results on a paper stripe. Three samples were examined. The first one was unused and the other two were used samples. One of the two samples was used during the first half of the experimental procedure and the other one during the second half. On each mica sample the roughness sampling implemented across the length of five $4,8 \mathrm{~mm}$ line segments. Three of these line segments were parallel to the large side of the rectangle and two of them were perpendicular to it. The calculated roughness parameters were the average roughness, the mean roughness depth and the maximum roughness depth and the respective results are shown below (Table I).

TABLE I. RESULTS OF SURFACE ROUGHNESS MEASUREMENTS

\begin{tabular}{|c|c|c|c|}
\hline \multirow{4}{*}{} & $\begin{array}{c}\text { Average } \\
\text { roughness } \\
\mathbf{R}_{\mathbf{a}}(\boldsymbol{\mu} \mathbf{m})\end{array}$ & $\begin{array}{c}\text { Mean } \\
\text { roughness } \\
\text { depth } \mathbf{R}_{\mathbf{z}} \\
(\boldsymbol{\mu} \mathbf{m})\end{array}$ & $\begin{array}{c}\text { Maximum } \\
\text { roughness } \\
\text { depth } \mathbf{R}_{\text {max }} \\
(\boldsymbol{\mu} \mathbf{m})\end{array}$ \\
\hline \multirow{4}{*}{$\begin{array}{c}\text { Unused } \\
\text { sample }\end{array}$} & 5.46 & 20.89 & 24.48 \\
\cline { 2 - 4 } & 3.31 & 14.91 & 28.48 \\
\cline { 2 - 4 } & 3.1 & 12.64 & 18.16 \\
\hline \multirow{4}{*}{$\begin{array}{c}\text { Used } \\
\text { sample 1 }\end{array}$} & 2.82 & 14.04 & 21.28 \\
\cline { 2 - 4 } & 4.69 & 21.37 & 31.68 \\
\cline { 2 - 4 } & 3.68 & 12.92 & 16.96 \\
\cline { 2 - 4 } & 4.86 & 14.33 & 17.28 \\
\hline \multirow{4}{*}{$\begin{array}{c}\text { Used } \\
\text { sample 2 }\end{array}$} & 4.86 & 19.71 & 30.40 \\
\cline { 2 - 4 } & 3.98 & 20.89 & 28.16 \\
\cline { 2 - 4 } & 3.18 & 17.37 & 21.92 \\
\cline { 2 - 4 } & 3.47 & 15.07 & 16.32 \\
\hline
\end{tabular}

Average roughness: the arithmetic average of the absolute values of the roughness profile ordinates:

$$
R_{a}=\frac{1}{I} \int_{o}^{I}|Z(x)| d x
$$

Mean roughness depth: the arithmetic mean value of the single roughness depths $\mathrm{R}_{\mathrm{zi}}$ of consecutive sample length:

$$
R_{z}=\frac{1}{n\left(R_{z 1}+R_{z 2}+\ldots+R_{z n}\right)}
$$

Maximum roughness depth: the largest single roughness depth within the evaluation length [6].

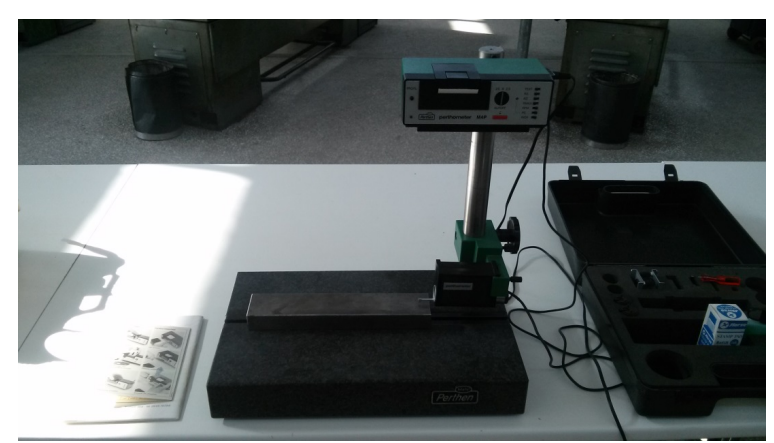

Fig. 3. Perthometer M4P. The measurements took place at the Machine Tools and Quality Control Laboratory of the Technological Educational Institute of Eastern Macedonia and Thrace.

\section{E. Experimental procedure}

The electrodes were positioned on the mica paper sample at a distance of $2.5 \mathrm{~cm}$. The water droplets were positioned between the electrodes by a syringe. The purpose of the experimental procedure was to measure the flashover voltage. The arrangements of the water droplets were the following:

- One $0.05 \mathrm{ml}$ droplet with a distance of $1.25 \mathrm{~cm}$ from the electrodes

- Two $0.05 \mathrm{ml}$ droplets with a distance of $0.8 \mathrm{~cm}$ from the nearest electrode and their centers

- Three $0.05 \mathrm{ml}$ droplets forming a triangle.

- Four $0.05 \mathrm{ml}$ droplets forming a square.

- One droplet of $0.1 \mathrm{ml}$ with a distance of $1.25 \mathrm{~cm}$ from the electrodes

- Two $0.1 \mathrm{ml}$ droplets with a distance of $0.8 \mathrm{~cm}$ from the nearest electrode and their centers (Figure 4)
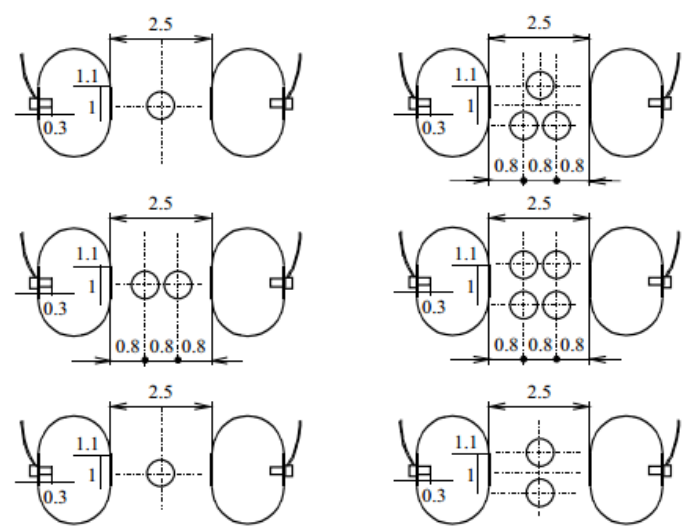

Fig. 4. The water droplet arrangements 
After putting the droplets on the mica paper the voltage was raised until flashover occurred. The value was recorded. After the flashover the surface and the electrodes were cleaned, new droplets were put and the voltage was raised at a value lower than the previous breakdown value by $1.2 \mathrm{kV}$. At this point the voltage stayed at this value for $5 \mathrm{~min}$. If no flashover occurred, the voltage was raised by $0.4 \mathrm{kV}$ and the procedure was repeated until flashover occurred. After the flashover the value was recorded. During the $5 \mathrm{~min}$ interval there was a smooth progress of the droplet oscillation and deformation until the occurrence of partial discharges and the flashover.

\section{EXPERIMENTAL RESULTS}

From the flashover voltage-conductivity diagrams it is understood that the flashover voltage depends on the number of droplets, their distance from the electrodes and their conductivity. As the number of the $0.05 \mathrm{ml}$ droplets is increased their distance from the electrodes is decreased leading to a flashover (Figures 5 and 6). The mica surface is highly hydrophilic and as a result the water droplets stick on it with a contact angle lower than $90^{\circ}$. Putting the droplets was quite difficult during the experiment due to the fact that they were spreading over the mica surface. Hydrophilicity might be the reason of this stability problem. A possible explanation is that the residual humidity on the mica surface did not let the water droplet be in contact with the mica. Thus, there were no adhesive forces to hold the droplets $[7,8]$.

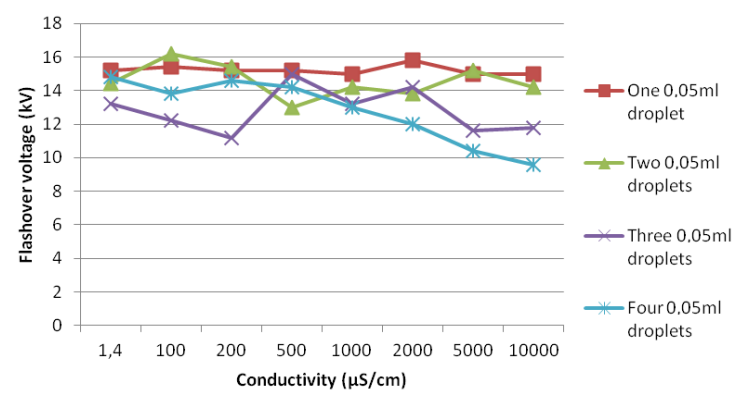

Fig. 5. Comparative results of the various droplet arrangements

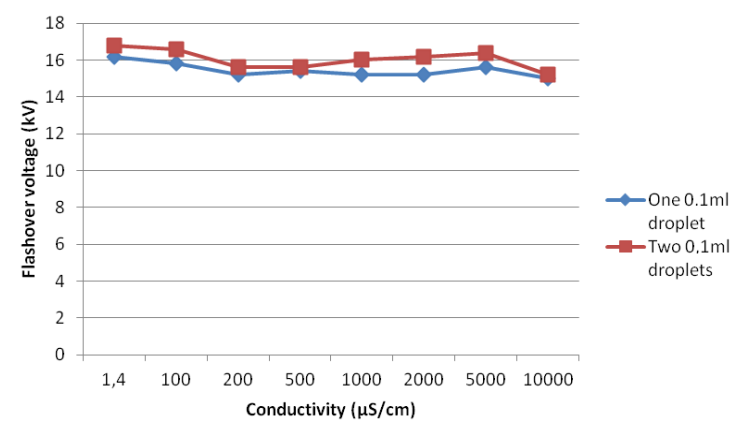

Fig. 6. Comparative results of two different droplet arrangements

Another crucial factor was the surface roughness on the mica paper samples. There are plenty of abnormalities on the mica paper surface forming hills and valleys of $\mu \mathrm{m}$ order. The water fills the space between the abnormalities and as a result the droplet movement is affected in two ways: i) the droplet is elongated across the surface valleys and, ii) the droplet spreading is blocked by the surface hills. The applied electric field made the droplets oscillate and emit sound waves. By raising the applied voltage the droplet oscillation and elongation became more intense. Some very common droplet types of behavior were the merging and the spreading of the adjacent droplets while some single droplets were moving close to the nearest electrode. The oscillation frequencies before the surface flashover were higher than $50 \mathrm{~Hz}$ (power grid frequency) and they were changing while the applied voltage was rising. The spectrum of the oscillation and flashover emitted sound signal was analyzed on Matlab. The spectrum analysis showed that the emitted frequencies were multiples of $100 \mathrm{~Hz}$ (twice the power frequency).

In order to understand the evolution of the emitted sound frequencies during the experiment a spectrogram was extracted. On the spectrogram one may see that the high frequency amplitudes increase before flashover occurs. The droplet oscillations were more intense and the flashover voltage decreased while the water salinity increased. After the surface flashover the water was spread on the mica paper bridging the two electrodes (Figures 7-9).

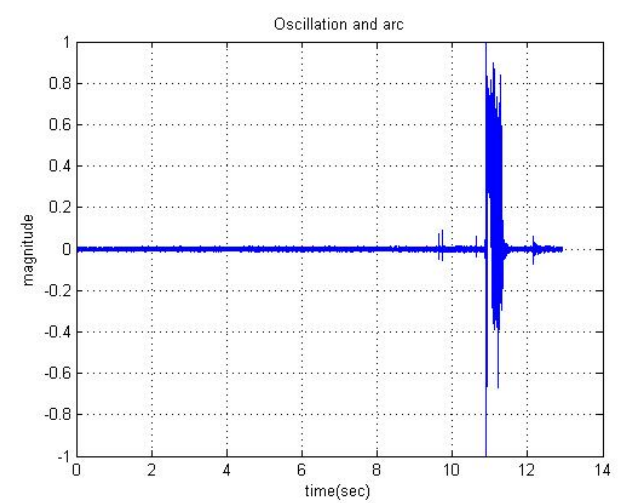

Fig. 7. The sound wave recorded during the experiment
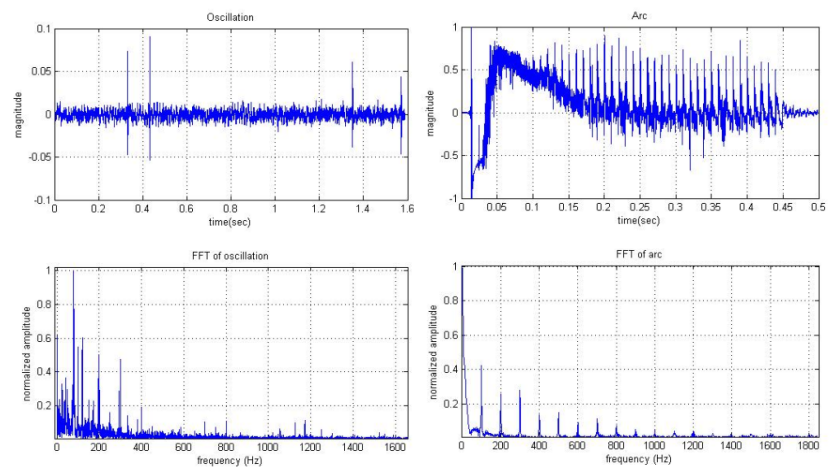

Fig. 8. Signals of the oscillations and the flashover and their FFT.

Looking at the mica paper samples there are no signs of degradation after the implementation of the experiment. Some surface changes shown after scanning the samples with the digital microscope Dino Lite Pro HR AM7000. The two used samples probably deteriorated by the electric arc by-products. 
The main arc by-products are the nitrogen monoxide and nitrogen dioxide. When nitrogen dioxide is combined with water, nitric acid is formed. The presence of nitric acid corrodes the mica surface since a substitution reaction occurs (mica's potassium is substituted by hydrogen and potassium nitrate is formed). Surface corrosion can also occur when particles are accelerated due to the partial discharges and bombardment of the surface. Thus, mica flakes get gradually delaminated. The differences between the images of the unused and used mica samples are shown below (Figures 10-12).

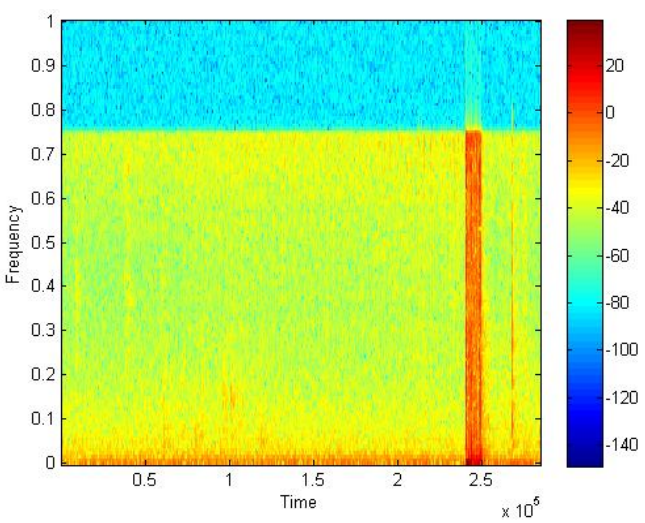

Fig. 9. Spectrogram of the emitted sound signal

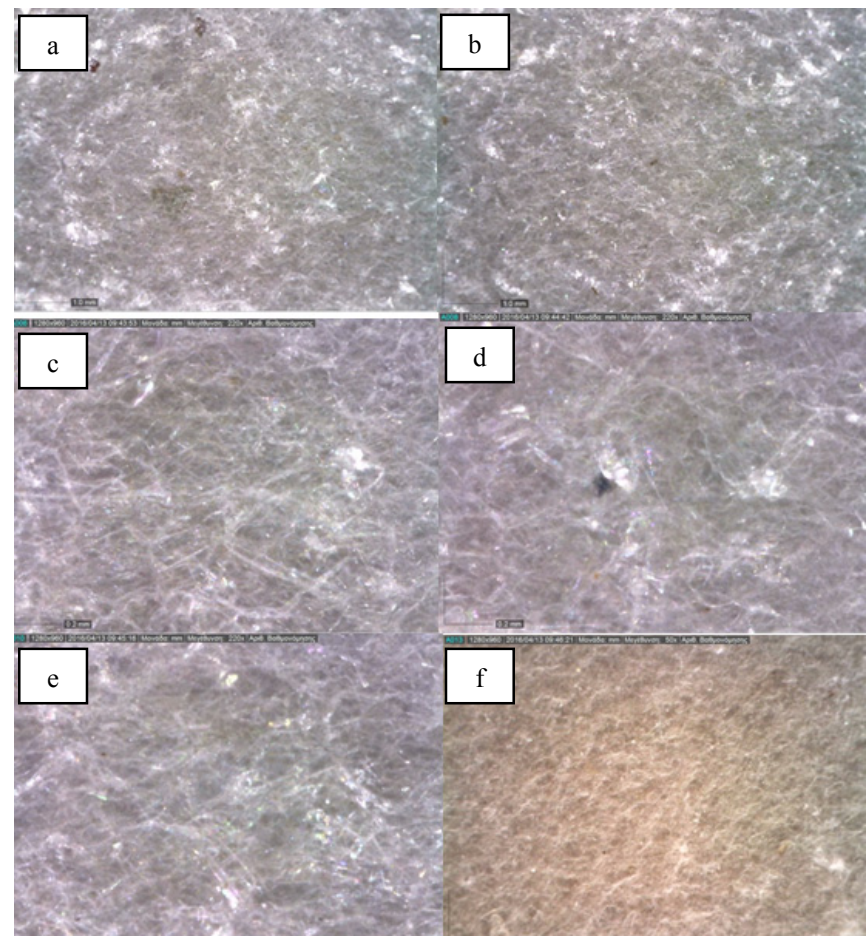

Fig. 10. Unused sample magnified by 50 times (photos $a, b$ and $\mathrm{f}$ ) and 200 times (photos $c, d$ and e). The f photo was taken without the microscope's light source. The relatively dark spots in the a and d photos are impurities of the mica structure

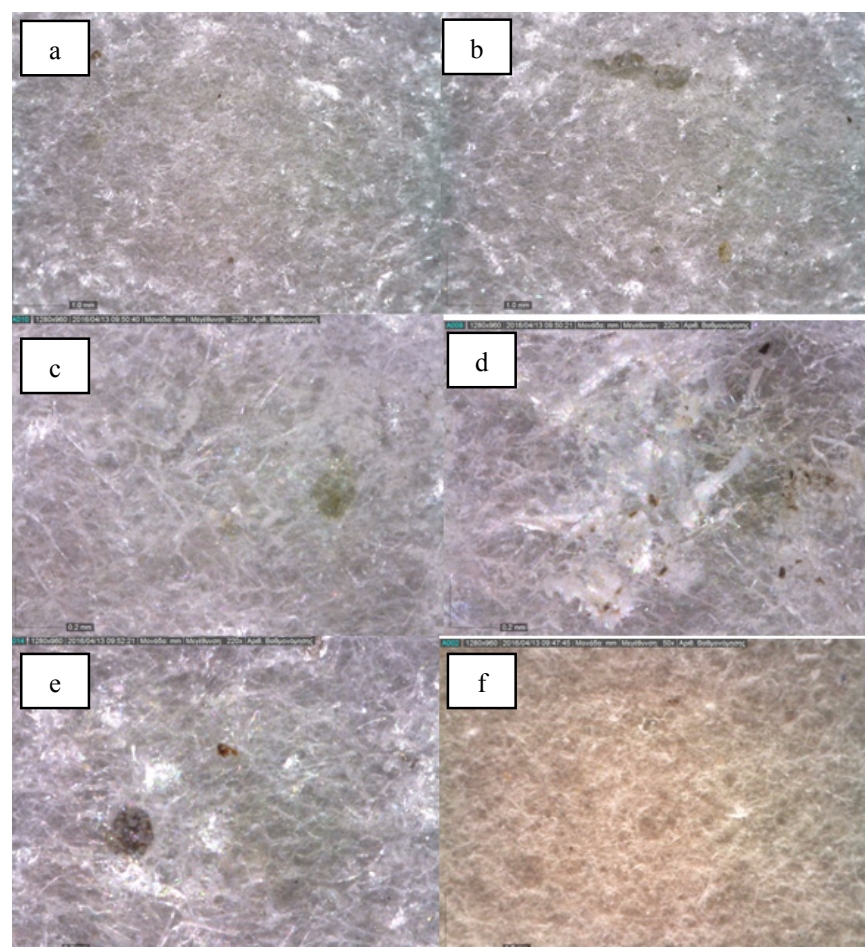

Fig. 11. The first used sample magnified by 50 times (photos a, b, f) and 220 times (photos $\mathrm{c}, \mathrm{d}, \mathrm{e}$ ). In the $\mathrm{d}$ and e images there are some indications of flake delamination and chemical degradation.

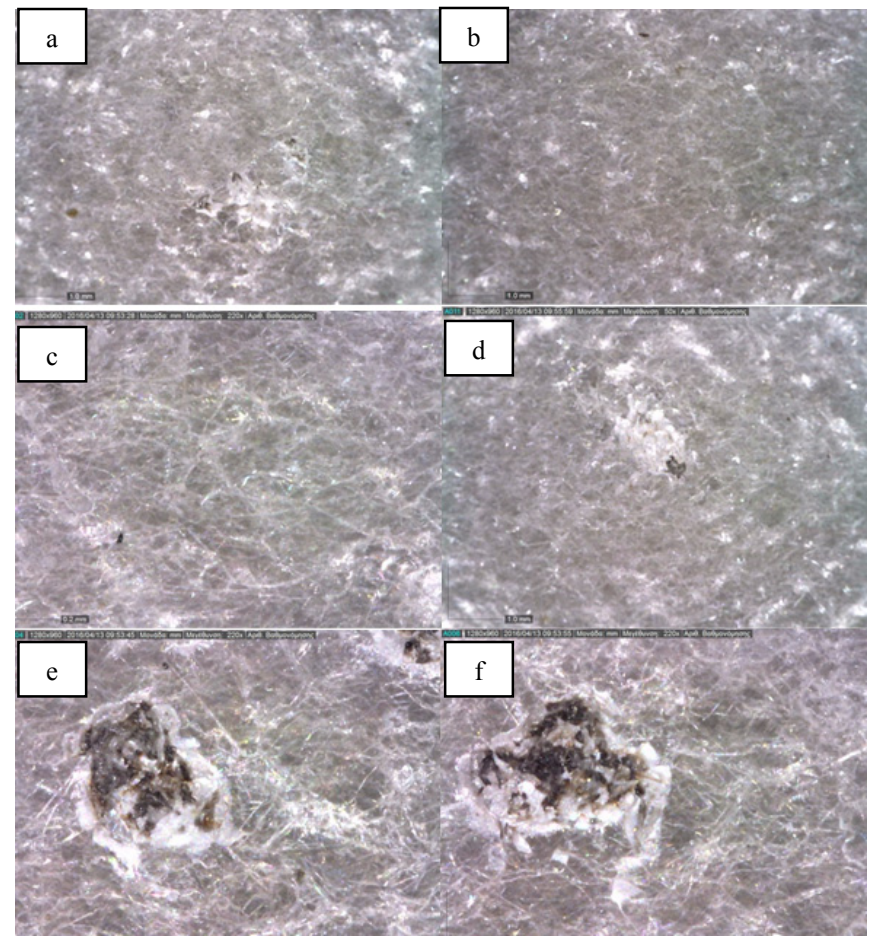

Fig. 12. The second used magnified by 50 times (photos a, b, d) and 220 times (photos $\mathrm{c}, \mathrm{e}, \mathrm{f}$ ). In the e and $\mathrm{f}$ photos the deterioration is obvious. 


\section{DISCUSSION}

In the present paper, a series of experiments were conducted on the basic insulating material of the electric machines. The measurements showed that among the factors determining the surface flashover are the conductivity, the number and the arrangement of the water droplets with respect to the electrodes, and the surface roughness on the insulation material. More specifically, it was observed that the flashover voltage of a single droplet with a volume of $0.05 \mathrm{ml}$ had the same value as the one of the single droplet with a volume of 0.1 $\mathrm{ml}$. Comparing the flashover voltages of the two droplets of $0.05 \mathrm{ml}$ and $0.1 \mathrm{ml}$ it was observed that the $0.1 \mathrm{ml}$ droplets had a larger flashover voltage although their overall droplet volume was the largest one. Additionally, the flashover voltages of the $0.5 \mathrm{ml}$ droplet arrangements (except for the $100 \mu \mathrm{S} / \mathrm{cm}$ droplets) were lower than the ones of the $0.01 \mathrm{ml}$. The increase of water conductivity tends to decrease the flashover voltage. On the other hand, the surface roughness contributes both to the decrease and the increase of the flashover voltage. The orientation of the surface abnormalities (hills and valleys) plays a crucial role regarding these procedures. There were some cases where the roughness was trapping the droplets and did not let them move towards the electrodes. In this case the flashover voltage tended to increase. In other cases, the roughness let the droplets elongate and move towards the electrodes. The result of this elongation was the creation of sharp edges where corona effect took place. In this case the flashover voltage decreased.

The experimental results presented here indicate that there is a relationship between flashover voltage and the above mentioned parameters. The effect of water conductivity, surface roughness, droplet volume and number of droplets was studied elsewhere with both traditional polymers materials and with nanocomposite materials [7-12]. The results of the present study are qualitatively not that different from the experimental results of the references [7-12]. One may object to the fact that in this paper only mica sheets were investigated and not mica sheets impregnated with epoxy resin. To this the reply is that mica sheets consist the main strong insulation component in an electrical machine insulation system and thus investigating water droplets on mica sheets to a great extent gives enough information regarding the electrical behavior of the whole system. A second objection may be that surface discharges and flashovers constitute a smaller danger to machine insulation than partial discharges. To this, the reply is that there is a great amount of published research on the aforementioned subject (e.g. [1-4]) and, nevertheless surface discharges and flashovers are also a danger to electrical machine insulation admittedly smaller but with no great amount of published work about this subject. Another parameter that affects the water droplet behavior was the frequency of the applied voltage. Electric motors are usually supplied by power electronic devices such as converters and inverters. This means that the applied frequency is variable. In a future research the behavior of water droplets under different frequencies and waveforms (e.g. PWM or SPWM) may be studied [13-15]. Experiments like the ones conducted in this paper can also take place on real stator bars insulated by mica, epoxy resin and glass fibers.

\section{CONCLUSIONS}

Flashover voltages on mica sheets were investigated under the influence of uniform electric fields and taking into account parameters, such as water droplet conductivity, positioning of the droplets w.r.t. the electrodes, mica surface roughness and droplet volume. The above mentioned parameters affect the flashover voltage in an expected way, except perhaps from the surface roughness, which on other occasions may provoke an increase of the flashover voltage and in other cases a decrease of it.

\section{REFERENCES}

[1] D. Kind, H. Kaerner, Insulating materials in high voltage technology, Eds. Vieweg \& Sohn, Braunschweig/Wiesbaden, 1985

[2] C. L. Wadhwa, High voltage engineering, Eds. New Age International (P) Limited, Publishers, New Delhi, 1994

[3] M. S. Naidu, V. Kamaraju, High voltage engineering, Eds. Tata McGraw-Hill Publishing Company Limited, New Delhi, 2000

[4] D. Koenig, Y. Narayana Rao, Teilentladungen in Betriebsmitteln der Energietechnik, Eds. Vde Verlag, Berlin und Offenbach, 1993

[5] S. Maslougkas, "Study of droplet behavior in electrical machine insulation", Diploma Thesis, Democritus University of Thrace, Department of Electrical \& Computer, Engineering, Power Systems Laboratory, Xanthi, Greece, 2017 (in Greek)

[6] Mahr GmbH, Perthometer. Surface texture parameters. New standards DIN EN ISO/ASME, Germany 1999

[7] M. G. Danikas, P. Rakitzis, K. Karakoulidis, "Study of parameters related to deterioration phenomena due to water droplets on polymeric surfaces", Journal of Electrical Engineering, Vol. 57, No. 3, pp. 130-137, 2006

[8] M. G. Danikas, P. Ramnalis, R. Sarathi, "A study of the behavior of water droplets on polymeric surfaces under the influence of electric fields in an inclined test arrangement", Journal of Electrical Engineering, Vol. 60, No. 2, pp. 94-99, 2009

[9] M. G. Danikas, "Surface phenomena on resin-type insulators under different electrical and non-electrical stresses in the early stage of ageing", Facta Universitatis, Vol. 13, No. 3, pp. 335-352, 2000

[10] Y. Cheng, X. Zhao, M. G. Danikas, D. Christantoni, P. Zairis, “A study of the behaviour of water droplets under the influence of uniform electric field in epoxy resin samples", Journal of Electrical Engineering, Vol. 63, No. 3, pp. 196-200, 2012

[11] A. Bairaktari, M. G. Danikas, X. Zhao, Y. Cheng, Y. Zhang, "Behaviour of water droplets under the influence of a uniform electric field in nanocomposite samples of epoxy resin/ $\mathrm{TiO}_{2}$,",Engineering, Technology \& Applied Science Research, Vol. 3, No. 5, pp. 511-515, 2013

[12] S. C. Kechagia, M. G. Danikas, R. Sarathi, "Water droplets and breakdown phenomena on polymer nanocomposite surfaces under the influence of uniform electric fields", Malaysian Polymer Journal, Vol. 8, No. 2, pp. 41-47, 2013

[13] A. Cavallini, D. Fabiani, G. C. Montanari, "Power electronics and electrical insulation systems - Part 1: Phenomenology overview", IEEE Electrical Insulation Magazine, Vol. 26, No. 3, pp. 7-15, 2010

[14] A. Cavallini, D. Fabiani, G. C. Montanari, "Power electronics and electrical insulation systems - Part 2: Life modelling for insulation design”, IEEE Electrical Insulation Magazine, Vol. 26, No. 4, pp. 33-39, 2010

[15] A. Cavallini, D. Fabiani, G. C. Montanari, "Power electronics and electrical insulation systems - Part 3: Diagnostic properties", IEEE Electrical Insulation Magazine, Vol. 26, No. 5, pp. 30-40, 2010 